\title{
A Robust Decentralized Load Frequency Controller for Interconnected Power Systems
}

\author{
Lili Dong \\ Cleveland State University, I.dong34@csuohio.edu
}

Yao Zhang

Cleveland State University

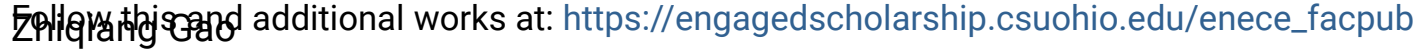

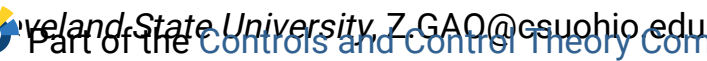
How does access to this work benefit you? Let us know!

\section{Publisher's Statement}

NOTICE: this is the author's version of a work that was accepted for publication in ISA Transactions. Changes resulting from the publishing process, such as peer review, editing, corrections, structural formatting, and other quality control mechanisms may not be reflected in this document. Changes may have been made to this work since it was submitted for publication. A definitive version was subsequently published in ISA Transactions, 51, 3, (05-01-2012); 10.1016/j.isatra.2012.02.004

\section{Original Citation}

L. Dong, Y. Zhang and Z. Gao, "A robust decentralized load frequency controller for interconnected power systems," ISA Trans., vol. 51, pp. 410-419, 5, 2012.

\section{Repository Citation}

Dong, Lili; Zhang, Yao; and Gao, Zhiqiang, "A Robust Decentralized Load Frequency Controller for Interconnected Power Systems" (2012). Electrical Engineering \& Computer Science Faculty Publications. 220.

https://engagedscholarship.csuohio.edu/enece_facpub/220

This Article is brought to you for free and open access by the Electrical Engineering \& Computer Science Department at EngagedScholarship@CSU. It has been accepted for inclusion in Electrical Engineering \& Computer Science Faculty Publications by an authorized administrator of EngagedScholarship@CSU. For more information, please contact library.es@csuohio.edu. 


\title{
A robust decentralized load frequency controller for interconnected power systems ${ }^{\text {मे }}$
}

\author{
Lili Dong*, Yao Zhang, Zhiqiang Gao \\ Department of Electrical and Computer Engineering, Cleveland State University, Cleveland, $\mathrm{OH} 44115$, USA
}

\section{Introduction}

A large-scale power system is composed of multiple control areas that are connected with each other through tie lines [1]. As active power load changes, the frequencies of the areas and tie-line power exchange will deviate from their scheduled values accordingly. As a result, the performance of the power system could be greatly degraded [2]. A local governor of the power system can partially compensate power load change through adjusting generator's output. However, with this type of governor, when the system load increases, the system frequency decreases and vice versa [3]. Therefore a supplementary controller is essential for the power system to maintain the system frequency at $60 \mathrm{~Hz}$ (a scheduled frequency in North America) no matter what the load is. This type of supplementary controller is called automatic generation control (AGC), or more specifically, load frequency control (LFC). For stable operation of power systems, both constant frequency and constant tile-line power exchange should be provided [4]. Therefore an Area Control Error (ACE), which is defined as a linear combination of power net-interchange and frequency deviations [1], is generally taken as the controlled output of LFC. As the ACE is driven to zero by the LFC, both frequency and tie-line power errors will be forced to zeros as well [1].
In the past six decades, there has been a significant amount of research conducted on LFCs. During the early stage of the research, LFC was based on centralized control strategy $[5,6]$. which has "the need to exchange information from control areas spread over distantly connected geographical territories along with their increased computational and storage complexities" [3]. In order to overcome the computational limitation, decentralized LFC has recently been developed, through which each area executes its control based on locally available state variables [7]. Among various types of decentralized LFCs, the most widely employed in power industry is PID control [8-13]. The PI controller tuned through genetic algorithm linear matrix inequalities (GALMIs) [11] becomes increasingly popular in recent years. PID controller is simple to implement but usually gives long settling time (about 10 to $30 \mathrm{~s}$ ) and produces large frequency deviation [14]. The PID controller introduced in [13] shows good performance in reducing frequency deviations. However, the robustness of the PID controller for multiple-area power system is not investigated in [13]. With the recent progress in control technologies, advanced controllers have come into adoption for load frequency controls. Due to the change of power flow conditions, parameters in a power system model fluctuate almost every minute [15]. To solve this problem, both $\mathrm{H}_{\infty}[16,17]$ and adaptive controllers $[18,19]$ are applied to the power system. The controllers not only identify parameter uncertainties but regulate the ACE. In addition, a $\mu$-synthesis controller was introduced in [20] to compensate modeling uncertainties. Fuzzy logic based LFC is presented in [21,22]. Such a controller is often combined with PI or PID controllers to optimally adjust PID gains. Most of the existing 


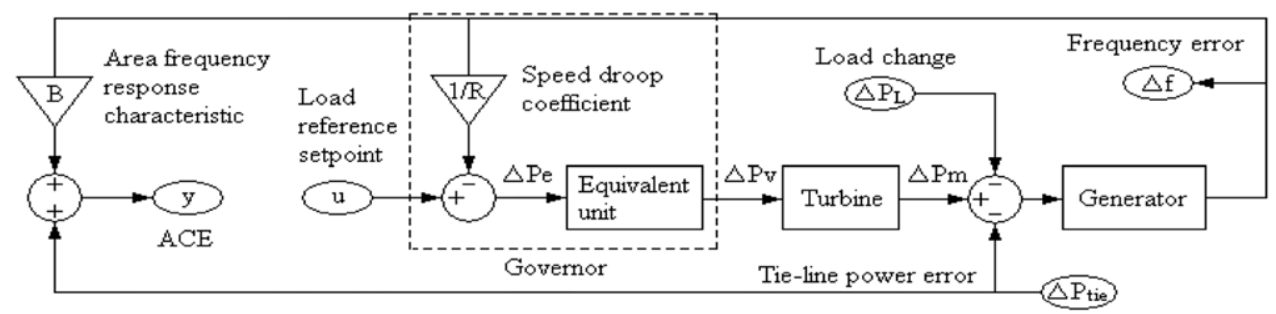

Fig. 1. Schematic of one-area power generating unit.

LFCs apply to the control areas comprising of thermal turbines, only a few of them $[13,16]$ treat both thermal and hydraulic turbines.

This paper presents a novel solution in the form of a decentralized robust LFC for a three-area interconnected power system. Its performance is evaluated in the presence of parameter uncertainties and large power load changes. The power system studied here contains reheat, non-reheat, and hydraulic turbine units, which are distributed in the three areas respectively. This solution is based on active disturbance rejection control (ADRC), an emerging control technology that estimate and mitigate uncertainties, internal and external, in real time, resulting in a controller that does not require accurate model information and is inherently robust against structural uncertainties commonly seen in power systems. Particularly, compared to other complex advanced controllers [15-21], the ADRC only has two tuning parameters, making it simple to implement in practice. So far the ADRC has been successfully employed in MEMS, power converter, and web tension [22-26]. In this paper, it is the first time that the ADRC is modified and applied to the power system with three different turbine units. Some preliminary results of the research were published in [27], where the performance of the ADRC was compared with a LMI tuned PID controller [12] for the power system with only non-reheat turbine units.

This paper is organized as follows. The dynamic modeling of the power system is given in Section 2. The ADRC design is introduced in Section 3. Simulation results are shown in Section 4. Stability analyses are presented in Section 5. The concluding remarks are made in Section 6.

\section{Dynamic model}

In this section, the dynamic model of a three-area interconnected power system is developed. As shown in Fig. 1, each area of the power system consists of one generator, one governor, and one turbine unit. The generator, governor, and turbine constitute a power generating unit. In addition, each area includes three inputs, which are the controller input $U(s)$ (also denoted as $u$ ), load disturbance $\Delta P_{L}(s)$, and tie-line power error $\Delta P_{\text {tie }}(s)$, one ACE output $Y(s)$, and one generator output $\Delta f$. In Fig. $1, \Delta P_{v}$ denotes valve position change, $\Delta P_{e}$ electrical power, and $\Delta P_{m}$ mechanical power. The ACE alone is a measurable output. For each area, it is defined by (1), where $B$ is area frequency bias setting [1].

$A C E=\Delta P_{\text {tie }}+B \Delta f$.

We use transfer function (TF) to model the one-area generator unit for the sake of convenience in frequency-domain analyses. Let the transfer function from $\Delta P_{e}(s)$ to $\Delta P_{m}(s)$ be $G_{E T}(s)=$ $\operatorname{Num}_{E T}(s) / \operatorname{Den}_{E T}(s)$, where $\operatorname{Num}_{E T}(s)$ and $\operatorname{Den}_{E T}(s)$ are the numerator and denominator polynomials, respectively, and they vary in different generating units. From [1], the TF of non-reheat turbine unit $\left(G_{E T}(s)\right)$ is given by

$G_{E T}(s)=\frac{\operatorname{Num}_{E T}(s)}{\operatorname{Den}_{E T}(s)}=\frac{1}{\left(T_{g} s+1\right)\left(T_{c h} s+1\right)}$.
From [1], the TF of reheat turbine unit is represented by

$G_{E T}(s)=\frac{\operatorname{Num}_{E T}(s)}{\operatorname{Den}_{E T}(s)}=\frac{F_{h p} T_{r h} s+1}{\left(T_{g} s+1\right)\left(T_{c h} s+1\right)\left(T_{r h} s+1\right)}$.

From [1], the TF of hydraulic turbine unit is

$$
\begin{aligned}
G_{E T}(s) & =\frac{\operatorname{Num}_{E T}(s)}{\operatorname{Den}_{E T}(s)} \\
& =\frac{\left(T_{R} s+1\right)\left(-T_{w} s+1\right)}{\left(T_{g} s+1\right)\left[T_{R}\left(R_{T} / R\right) s+1\right]\left[\left(T_{w} / 2\right)+1\right]} .
\end{aligned}
$$

According to [1], the TF of the generator is

$G_{G e n}(s)=\frac{1}{\operatorname{Den}_{M}(s)}=\frac{1}{M s+D}$

The parameters in (2)-(5) are defined in Table 6 of Appendix. From Fig. 1, the output $Y(s)$ for each area can be represented by

$Y(s)=G_{P}(s) U(s)+G_{D}(s) \Delta P_{L}(s)+G_{t i e}(s) \Delta P_{\text {tie }}(s)$,

where $G_{p}(s), G_{D}(s)$, and $G_{t i e}(s)$ are the TFs between the three inputs $\left(U(s), \Delta P_{L}(s)\right.$, and $\left.\Delta P_{t i e}(s)\right)$ and ACE output $(Y(s))$. The three transfer functions in (6) are expressed as

$\begin{aligned} & G_{P}(s)=\frac{\operatorname{RBNum}_{E T}(s)}{\operatorname{Num}_{E T}(s)+\operatorname{RDen}_{E T}(s) \operatorname{Den}_{M}(s)} \\ & G_{D}(s)=\frac{-\operatorname{RBDen}_{E T}(s)}{\operatorname{Num}_{E T}(s)+\operatorname{RDen}_{E T}(s) \operatorname{Den}_{M}(s)} \\ & G_{t i e}(s)=\frac{\operatorname{Num}_{E T}(s)+R \operatorname{Ren}}{E T}(s) \operatorname{Den}_{M}(s)-\operatorname{RBDen}_{E T}(s) \\ & \operatorname{Num}_{E T}(s)+\operatorname{RDen}_{E T}(s) \operatorname{Den}_{M}(s)\end{aligned}$

where $\operatorname{Num}_{E T}(s)$ and $\operatorname{Den}_{E T}(s)$ have different expressions (as shown in (2)-(4)) corresponding to different turbine units.

The proposed ADRC-based control system is shown in Fig. 2. Under a decentralized control strategy, the ADRC controller is placed in each area acting as local LFC. Three decentralized areas are connected to each other through tie lines. Non-reheat, reheat and hydraulic turbine units are distributed in the three areas orderly. The parameter values of the system are obtained from $[1,15]$ and are listed in Table 7 in Appendix. Substituting the parameter values into the $G_{p}(s)$ between the controller input $U(s)$ and ACE output, we will have

$$
\begin{aligned}
G_{P N}(s) & =\frac{1.05}{0.015 \mathrm{~s}^{3}+0.2015 \mathrm{~s}^{2}+0.52 \mathrm{~s}+1.05} \\
G_{P R}(s) & =\frac{2.205 \mathrm{~s}+1.05}{0.21 \mathrm{~s}^{4}+1.801 \mathrm{~s}^{3}+3.928 \mathrm{~s}^{2}+2.975 \mathrm{~s}+1.05} \\
G_{P H}(s) & =\frac{-5.25 \mathrm{~s}^{2}+4.2 \mathrm{~s}+1.05}{1.14 \mathrm{~s}^{4}+8.2 \mathrm{~s}^{3}+7.945 \mathrm{~s}^{2}+6.235 \mathrm{~s}+1.05},
\end{aligned}
$$

where $G_{P N}(s)$ denotes the TF for area $1, G_{P R}(s)$ the TF for area 2, and $G_{P H}(s)$ the TF for area 3. From (12), we can see that the transfer function of hydraulic unit has a positive zero, which can bring instability to the system. This problem can be solved by fine tuning the controller parameters. The system with hydraulic turbine unit will be stabilized by the controller as well. The controller design and parameter tuning are introduced in the following section. 


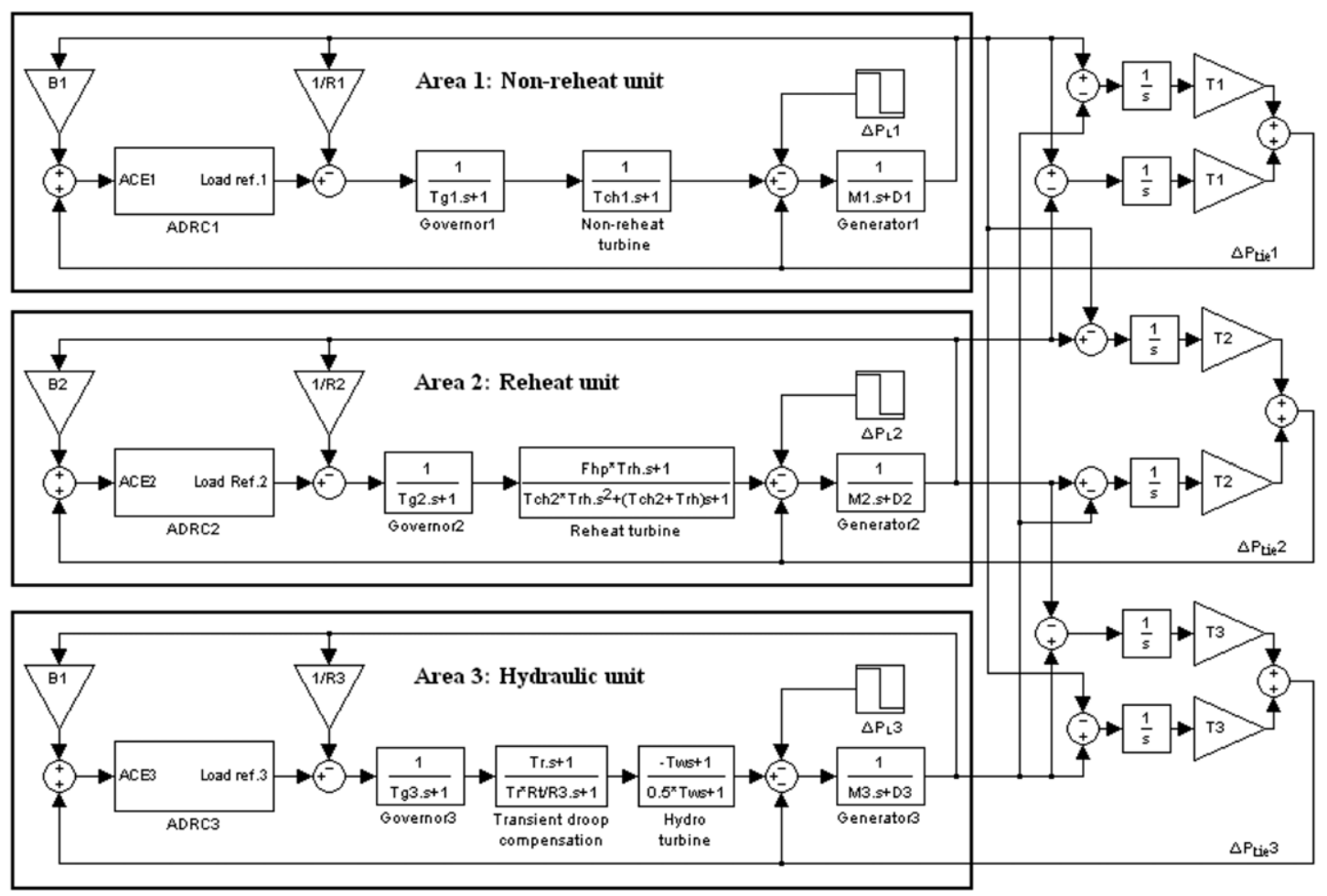

Fig. 2. Three-area power system with different turbine units.

\section{The LFC design}

We choose ADRC as decentralized LFC for the interconnected power system. The basic idea of the time-domain ADRC is introduced in [24]. In this section, the TF representation of the ADRC will be developed for a general $n$-th order plant.

\subsection{Transfer function derivation of $n$-th order plant}

A plant with disturbance can be represented by

$Y(s)=G_{p}(s) \cdot U(s)+W(s)$,

where $U(s)$ and $Y(s)$ are the input and output respectively, and $W(s)$ is the generalized disturbance including unknown internal dynamics and external disturbances [24]. In (13), the TF of the general physical plant $G_{p}(s)$ can be described as

$$
\begin{aligned}
\frac{Y(s)}{U(s)} & =G_{P}(s) \\
& =\frac{b_{m} s^{m}+b_{m-1} s^{m-1}+\cdots+b_{1} s+b_{0}}{a_{n} s^{n}+a_{n-1} s^{n-1}+\cdots+a_{1} s+a_{0}}, \quad n \geq m,
\end{aligned}
$$

where $a_{i}$ and $b_{j}(i=1, \ldots, n, j=1, \ldots, m)$ are the coefficients of $G_{p}(s)$. Making both sides of (13) divided by $G_{p}(s)$, we will have

$\left(1 / G_{p}(s)\right) Y(s)=U(s)+W^{\prime}(s)$,

where $W^{\prime}(s)=W(s) / G_{p}(s)$. In (15), $1 / G_{p}(s)$ can be obtained as

$$
\begin{aligned}
\frac{1}{G_{P}(s)}= & \frac{a_{n} s^{n}+a_{n-1} s^{n-1}+\cdots+a_{1} s+a_{0}}{b_{m} s^{m}+b_{m-1} s^{m-1}+\cdots+b_{1} s+b_{0}} \quad(n \geq m) \\
= & c_{n-m} s^{n-m}+c_{n-m-1} s^{n-m-1}+\cdots+c_{1} s \\
& +c_{0}+G_{\text {left }}(s),
\end{aligned}
$$

where $c_{i}(i=0, \ldots, n-m)$ are coefficients of the polynomial $1 / G_{p}(s)$, and the remainder $G_{\text {left }}(s)$ is

$G_{\text {left }}(s)=\frac{d_{m-1} s^{m-1}+d_{m-2} s^{m-2}+\cdots+d_{1} s+d_{0}}{b_{m} s^{m}+b_{m-1} s^{m-1}+\cdots+b_{1} s+b_{0}}$.
In (17), $d_{j}(j=0, \ldots, m-1)$ are coefficients of the numerator of the remainder. Substituting (16) into (15), we have

$$
\begin{aligned}
& {\left[c_{n-m} s^{n-m}+c_{n-m-1} s^{n-m-1}+\cdots+c_{1} s+c_{0}+G_{\text {left }}(s)\right] Y(s)} \\
& \quad=U(s)+W^{\prime}(s),
\end{aligned}
$$

where

$c_{n-m}=\frac{a_{n}}{b_{m}}$.

Eq. (18) can be rewritten as

$$
\begin{aligned}
c_{n-m} s^{n-m} Y(s)= & U(s)-\left[c_{n-m-1} s^{n-m-1}+\cdots+c_{1} s\right. \\
& \left.+c_{0}+G_{\text {left }}(s)\right] Y(s)+W^{\prime}(s) .
\end{aligned}
$$

Making both sides of (20) divided by $c_{n-m}$, we will have

$s^{n-m} Y(s)=b U(s)+D(s)$,

where $b=1 / c_{n-m}$, and a modified generalized disturbance is

$$
\begin{aligned}
D(s)= & -\frac{1}{c_{n-m}}\left[c_{n-m-1} s^{n-m-1}+\cdots+c_{1} s\right. \\
& \left.+c_{0}+G_{\text {left }}(s)\right] Y(s)+\frac{1}{c_{n-m}} W^{\prime}(s) .
\end{aligned}
$$

We will take (21) as the system model for controller design.

\subsection{Design of extended state observer}

From [24], the effectiveness of the ADRC is dependent on accurate estimation of the generalized disturbance $D(s)$. Consequently an Extended State Observer (ESO) needs to be developed to estimate the $D(s)$ in real time. This can be achieved by augmenting the state variables of the system (21) to include $D(s)$. Let $x_{1}(s)=Y(s)$. In order to construct the ESO, the system model (21) is rewritten as

$s X(s)=A X(s)+B U(s)+E s D(s)$

$Y(s)=C X(s)$ 
where

$X(s)=\left[\begin{array}{c}x_{1}(s) \\ x_{2}(s) \\ \vdots \\ x_{n-m}(s) \\ x_{n-m+1}(s)\end{array}\right]$

$A=\left[\begin{array}{ccccc}0 & 1 & 0 & \cdots & 0 \\ 0 & 0 & 1 & \cdots & 0 \\ \vdots & \vdots & \vdots & \ddots & \vdots \\ 0 & 0 & 0 & \cdots & 1 \\ 0 & 0 & 0 & \cdots & 0\end{array}\right]$

$B=\left[\begin{array}{c}0 \\ \vdots \\ 0 \\ b \\ 0\end{array}\right]_{(n-m+1) \times 1} E=\left[\begin{array}{c}0 \\ \vdots \\ 0 \\ 0 \\ 1\end{array}\right]_{(n-m+1) \times 1}$

$C=\left[\begin{array}{lllll}1 & 0 & 0 & \cdots & 0\end{array}\right]_{1 \times(n-m+1)}$.

We assume that $D(s)$ has the local Lipschitz continuity and $s D(S)$ is bounded within domain of interests. Then the ESO is

$s Z(s)=A Z(s)+B U(s)+L(Y(s)-\hat{Y}(s))$

$\hat{Y}(s)=C Z(s)$

where $Z(s)$ is the estimated state vector and $Z(s)=\left[z_{1}(s) z_{2}(s) \ldots\right.$ $\left.z_{n-m}(s) z_{n-m+1}(s)\right]^{T}$, and $L$ is the observer gain vector and $L=\left[\begin{array}{lllll}\beta_{1} & \beta_{2} & \ldots & \beta_{n-m} & \beta_{n-m+1}\end{array}\right]^{T}$. In order to locate all the eigenvalues of the ESO to $-\omega_{0}$, the observer gains are chosen as

$\beta_{i}=\left(\begin{array}{c}n-m+1 \\ i\end{array}\right), \quad i=1, \ldots, n-m+1$.

Therefore we can change the observer gains through tuning the parameter $\omega_{0}$, which is also the bandwidth of the observer. With a well tuned ESO, $z_{i}(s)$ will be able to estimate the value of $x_{i}(s)$ closely $(i=1, \ldots, n-m+1)$. Then we have

$z_{n-m+1}(s)=\hat{D}(s) \approx D(s)$,

where $\hat{D}(s)$ represents estimated $D(s)$.

\subsection{Design of $A D R C$}

If the control input is designed as

$U(s)=\left(U_{0}(s)-z_{n-m+1}(s)\right) / b$,

the original system (21) will be reduced to a pure integral plant.

This process can be demonstrated by $(28)$, where $U_{0}(s)$ is the control law for regulating the ACE output $Y(s)$.

$$
\begin{aligned}
s^{n-m} Y(s) & =b \cdot\left[\left(U_{0}(s)-z_{n-m+1}(s)\right) / b\right]+D(s) \\
& =U_{0}(s)-\hat{D}(s)+D(s) \approx U_{0}(s) .
\end{aligned}
$$

The control goal of LFC is to regulate the ACE to zero. A traditional PD controller can reach this goal. So the control law $U_{0}(s)$ is chosen as

$U_{0}(s)=k_{0}\left(R(s)-z_{1}(s)\right)-k_{1} z_{2}(s)-\cdots k_{n-m-1} z_{n-m-1}(s)$,

where $R(s)$ is a reference input. With the control law in (29), $Y(s)$ will be drive to $R(s)$, which is zero for the LFC. To further simplify the tuning process, all the closed-loop poles of the PD controller are set to $-\omega_{c}$. Then the controller gains in (29) have to be selected as

$k_{i}=\left(\begin{array}{c}n-m \\ i\end{array}\right) \omega_{c}^{n-m-i}, \quad i=0,1, \ldots, n-m-1$.
Table 1

ADRC parameters of the first test system.

\begin{tabular}{lllll}
\hline & Order of ESO & $\omega_{C}$ & $\omega_{0}$ & $b$ \\
\hline Area 1 & 3 & 4 & 20 & 70.0 \\
Area 2 & 3 & 4 & 20 & 10.5 \\
Area 3 & 3 & 4 & 20 & 460 \\
\hline
\end{tabular}

\section{Simulation results}

In this section, the effectiveness of the ADRC is tested through two kinds of decentralized power systems. The first power system, as shown in Fig. 2, consists of three different generating units, each of which contains different turbine unit such as reheat, non-reheat, or hydraulic type. The second power system was proposed in [11]. It includes nine similar non-reheat turbine units that are evenly distributed in the three interconnected areas respectively. The second power system is mainly used to compare the control performance of the ADRC with that of the GALMI tuned PI controller introduced in [11].

4.1. On the three-area interconnected power system with different generating units

According to the discussions in Section 3, the ADRC for area 1 can be designed and represented by the following equations.

$s Z(s)=(A-L C) Z(s)+B U(s)+L Y(s)$

$U_{0}(s)=k_{0}\left(R(s)-z_{1}(s)\right)-k_{1} z_{2}(s)-k_{2} z_{3}(s)$

$U(s)=\frac{U_{0}(s)-z_{4}(s)}{b}$,

where

$Z(s)=\left[\begin{array}{l}z_{1}(s) \\ z_{2}(s) \\ z_{3}(s) \\ z_{4}(s)\end{array}\right], \quad A=\left[\begin{array}{llll}0 & 1 & 0 & 0 \\ 0 & 0 & 1 & 0 \\ 0 & 0 & 0 & 1 \\ 0 & 0 & 0 & 0\end{array}\right], \quad B=\left[\begin{array}{l}0 \\ 0 \\ b \\ 0\end{array}\right]$,

$L=\left[\begin{array}{c}4 \omega_{0} \\ 6 \omega_{0}^{2} \\ 4 \omega_{0}^{3} \\ \omega_{0}^{4}\end{array}\right], \quad k_{0}=\omega_{c}^{3}$,

$k_{1}=3 \omega_{c}^{2}, k_{2}=3 \omega_{c}$, and $C=\left[\begin{array}{llll}1 & 0 & 0 & 0\end{array}\right]$. The ADRCs for the other two areas have the similar structure to the one for area 1. The controller parameters of the ADRCs in different areas are given in Table 1. According to [28], the observer bandwidth $\left(\omega_{0}\right)$ is chosen as five times controller bandwidth $\left(\omega_{c}\right)$. The controller gain $b$ for area 3 is relatively large compared to the gains for the other two areas. This is for compensating the effects of the positive zero in area 3 . In Table 1 , there are only two tuning parameters for the ADRC design. They are the controller bandwidth $\left(\omega_{c}\right)$ and controller gain $(b)$.

The performance of ADRC is tested for two cases. In these two cases, a 0.1 p.u. (per unit) step load change is applied to the three different areas at $t=2,7$, and $12 \mathrm{~s}$ respectively. In different cases, the parameter values of the non-reheat unit in area 1 will have variant values. However, the controller parameter values of the ADRC, as listed in Table 1, remain unchanged in the following two cases.

In case 1 , the parameters of the non-reheat unit in area 1 are chosen to have nominal values. The effectiveness of ADRC is tested in this case by simulating the closed-loop control system in Fig. 2. In our simulation results, area 1 is denoted as the area with nonreheat unit (or non-reheat), area 2 the area with reheat unit (or reheat), and area 3 the area with hydraulic unit (or hydraulic). The 


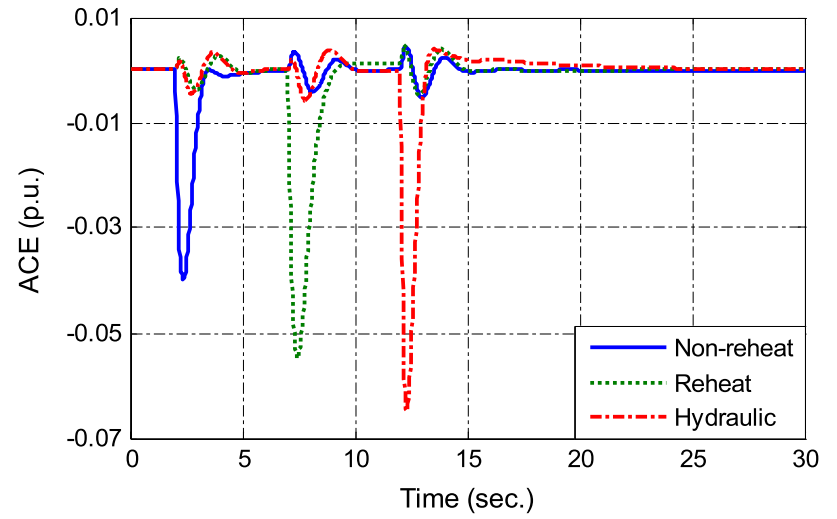

Fig. 3. ACEs of the three-area power systems.

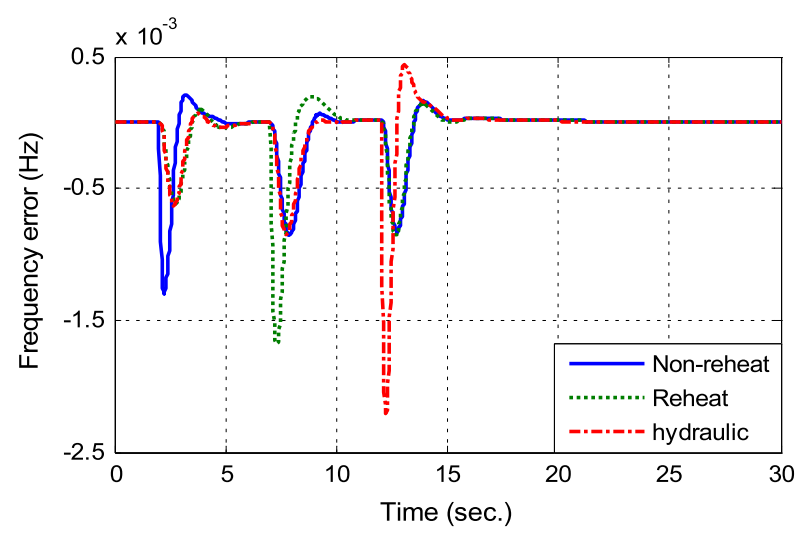

Fig. 4. Frequency errors of the three-area power systems.

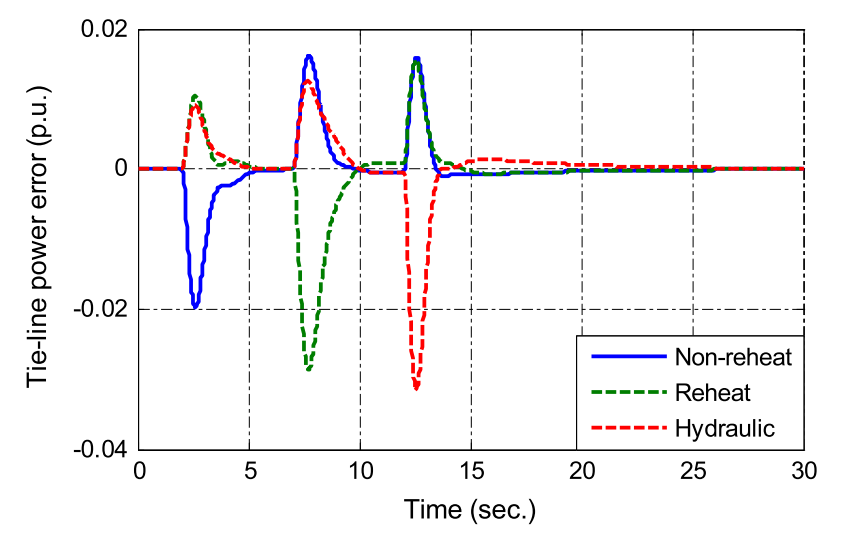

Fig. 5. Tie-line power errors of the three-area power systems.

system responses for three different areas are shown in Figs. 35 . From these three figures, we can see that the ACEs, frequency errors $(\Delta f)$, and tie-line power deviations have been successfully driven to zeros by ADRC in the presences of power load changes. The average settling time $\left(T_{s}\right)$ for the three systems is around $3 \mathrm{~s}$. The $T_{S}$ is much shorter than the one in the PID controlled system in [9-13]. The responses of area 3 have relatively large overshoots compared to the other two areas. We believe this is because the hydraulic unit is inherently unstable. The instability could cause the big oscillation during the transient period.

In case 2 , in order to test the robustness of ADRC, the variations of all of the parameters $\left(M_{1}, D_{1}, T_{c h 1}, T_{g 1}, R_{1}\right.$, and $\left.T_{1}\right)$ of the nonreheat unit in the first area are assumed to be $-20 \%$ and $20 \%$ of their nominal values respectively. However, the controller parameters of ADRC are not changed with the changes of system

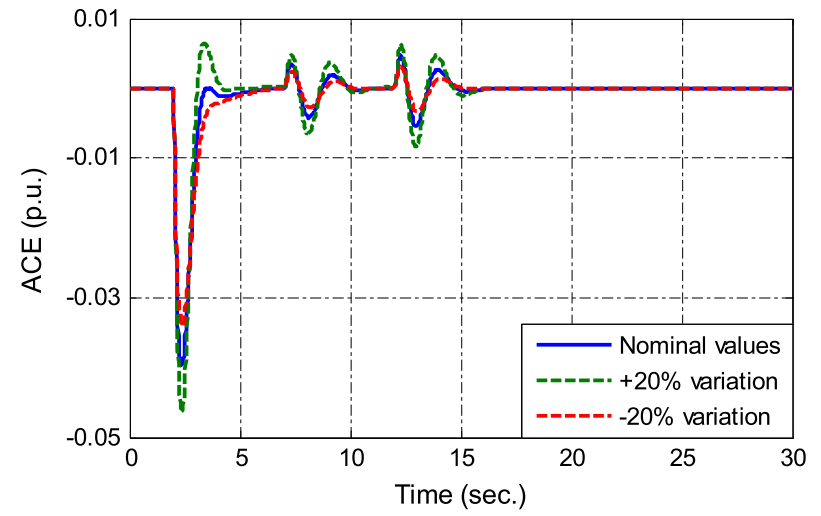

Fig. 6. ACEs of area 1 with variant parameter values.

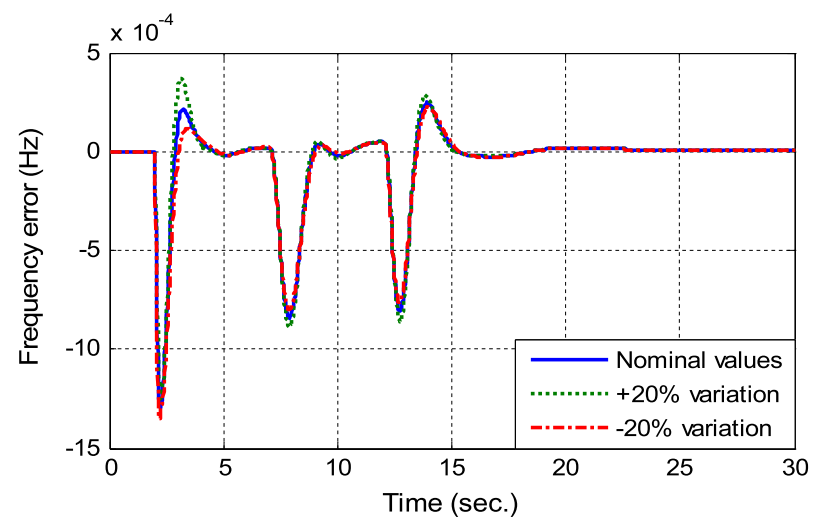

Fig. 7. Frequency errors of area 1 with parameter uncertainties.

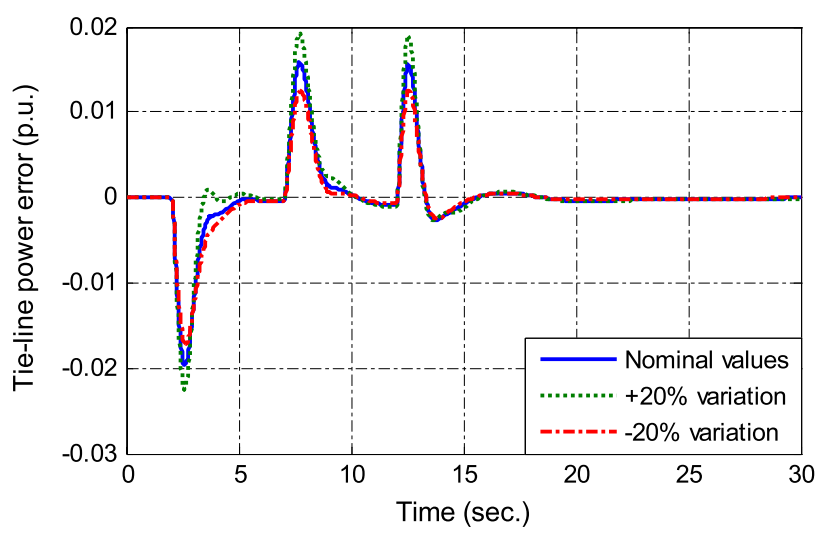

Fig. 8. Tie-line power errors of area 1 with variant parameter values.

parameters. The responses of area 1 are shown in Figs. 6-8 which illustrate the ACE outputs, frequency errors, and tie-line power errors of area 1 orderly with the variant parameter values for the non-reheat unit. From the simulation results, we can see that despite such large parameter variations, the system responses do not show notable differences from the results in Figs. 35. Therefore the simulation results demonstrate the robustness of ADRC against system parameter variations. When we change the system parameters for reheat and hydraulic units, the same conclusion is obtained.

\subsection{On the three-area interconnected power system with only non- reheat generating units}

The second power system also has three areas. Each area has three generating units that are owned by different generation 


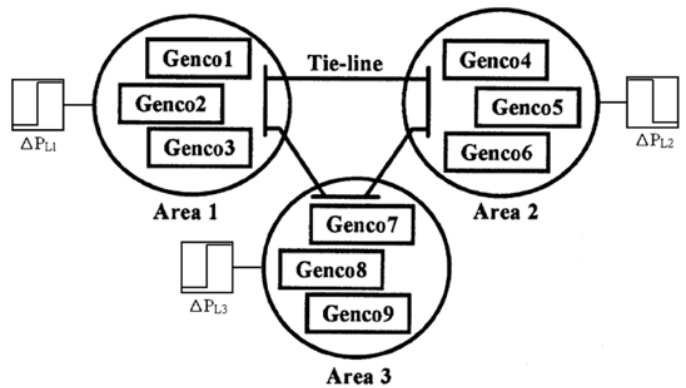

Fig. 9. Schematic of the three-area non-reheat power system. Source: Redrawn from [24].

companies (GenCos). Every generating unit consists of a nonreheat turbine unit, a generator, and a governor. The schematic diagram of the system is shown in Fig. 9, where the three areas are connected with each other through tie lines. In this figure, $\Delta P_{L 1}, \Delta P_{L 2}$, and $\Delta P_{L 3}$ are the power load changes added to the three areas. The dynamic model of area 1 is shown in Fig. 10, which is similar to the model in [11], where the GALMI tuned PI controller was proposed. In Fig. 10, the parameters $M_{\text {area } 1}$ (inertia constant for area 1 ) and $D_{\text {area } 1}$ (load damping constant for area 1) are equivalent to the parameters " $M$ " and " $D$ " in [11] for the generator model. We choose a system model similar to the one in [11] for the comparison of the performances between the GALMI tuned PI controller and ADRC controller.

The tie-line synchronizing coefficients between any two areas are $T_{12}=0.2$ p.u. $/ \mathrm{rad} ., T_{23}=0.12 \mathrm{p} . \mathrm{u} . / \mathrm{rad}$. and $T_{13}=$ $0.25 \mathrm{p} . \mathrm{u}$. $/ \mathrm{rad}$. The ramp rate factor that is used to describe the rate of change for the power plant output is given as

$\alpha=\frac{\text { Ramprate } \times 5 \mathrm{~min}}{\text { Regulation requirement }}$,

in which the regulation requirement for each area is $100 \mathrm{MW}$.

The ramp rate and all the other parameters of the system can be found in $[11,29]$. ADRC based controller is implemented on each area of the system in Fig. 10. The controller parameters for both ADRC and GALMI tuned PID controller are listed in Tables 2 and 3 respectively.

In this section, the performance of ADRC is compared with that of the GALMI tuned PI controller in [11] for three cases of load changes.

In case 1 , the random load changes $\left(P_{L i}\right)$, shown in Fig. 11, are added to each area of the power systems. Figs. 12-14 show the ACE
Table 2

ADRC parameters of the second test system.

\begin{tabular}{lllll}
\hline & Order of ESO & $\omega_{\mathrm{C}}$ & $\omega_{0}$ & $b$ \\
\hline Area 1 & 3 & 4 & 20 & 78.7739 \\
Area 2 & 3 & 4 & 20 & 76.2598 \\
Area 3 & 3 & 4 & 20 & 74.2768 \\
\hline
\end{tabular}

Table 3

GALMI tuned PI controller parameters.

\begin{tabular}{llll}
\hline & Area 1 & Area 2 & Area 3 \\
\hline$K_{p}$ & $-3.27 \times 10^{-4}$ & $-6.96 \times 10^{-4}$ & $-1.60 \times 10^{-4}$ \\
$K_{i}$ & -0.3334 & -0.3435 & -0.3398
\end{tabular}
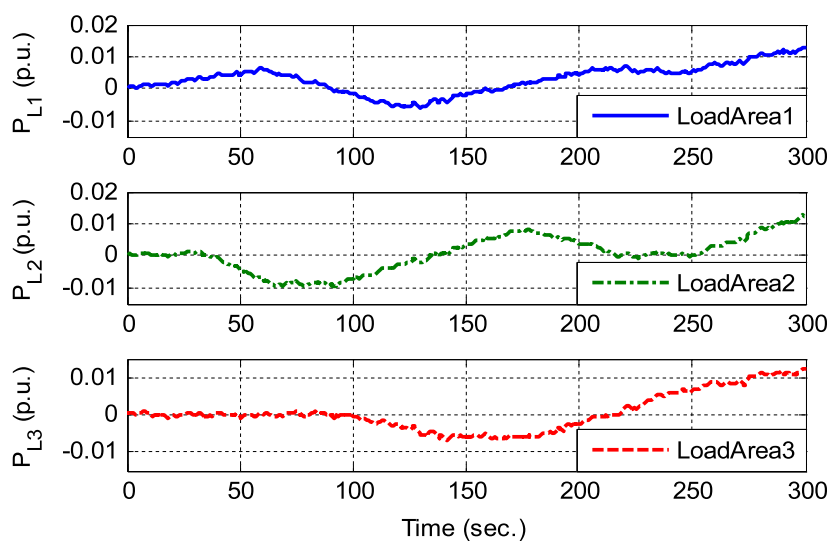

Fig. 11. Random load changes.

output, load frequency deviation $\Delta f$ and the difference between control effort and load disturbance, which is $\Delta \operatorname{Perr}(\triangle \operatorname{Perr}=$ $\triangle P C-\triangle P L)$ for both ADRC and PI controlled systems. From the simulations, we can see that both ADRC and the GALMI tuned PI controller can compensate the load fluctuations reflected by $\Delta$ Perr rapidly. However, the ACE, $\Delta f$, and $\triangle P e r r$ for ADRC controller have less peak errors (the peak errors of the ACE and $\triangle f$ for ADRC are no more than $0.05 \%$ ) than the GALMI tuned PI controller. ADRC controlled system shows better transient responses than the PI controlled system.

In case 2, a step load change with large amplitude is added to each area. The purpose of this case is to test the robustness of the controllers against large disturbances. The amplitudes of the load changes for the three areas are $\Delta P_{L 1}=100 \mathrm{MW}(0.1$ p.u. $)$,

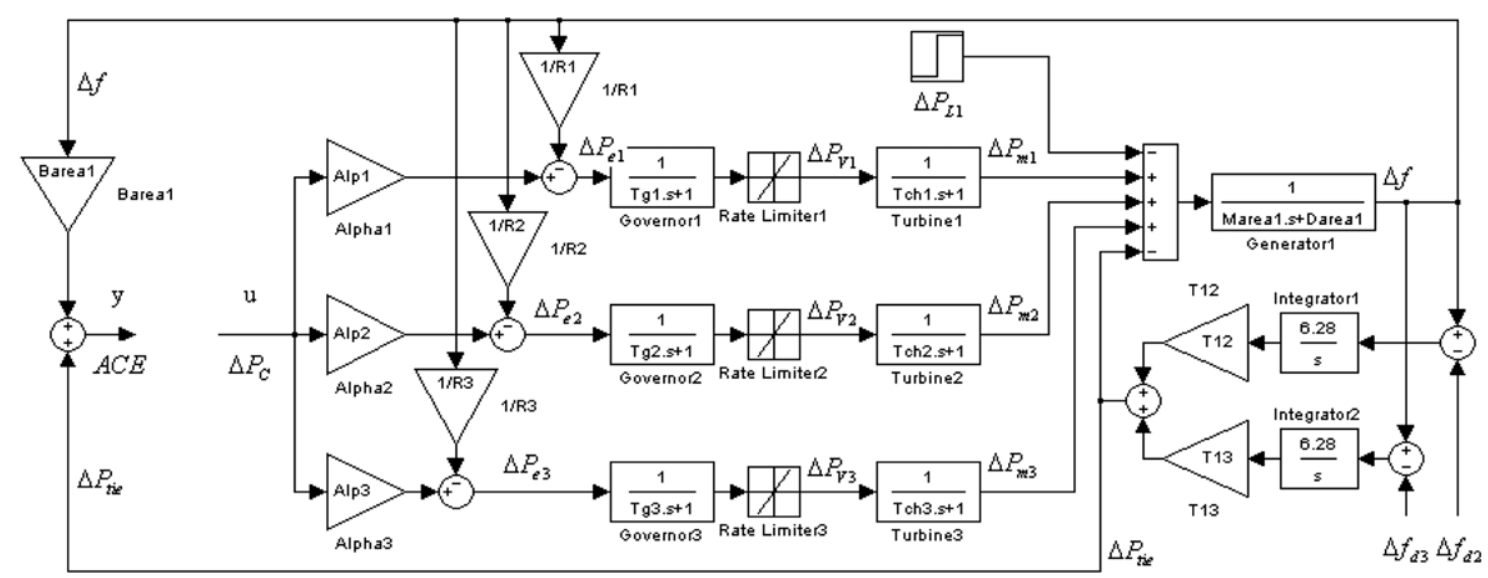

Fig. 10. Dynamic model of one area for the second test system. Source: Redrawn from [11]. 

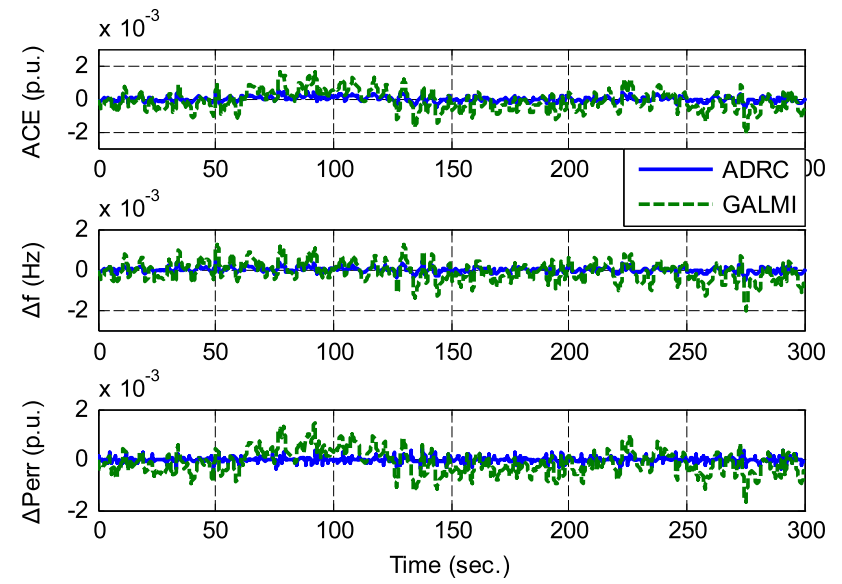

Fig. 12. System responses of area 1 for case 1 .
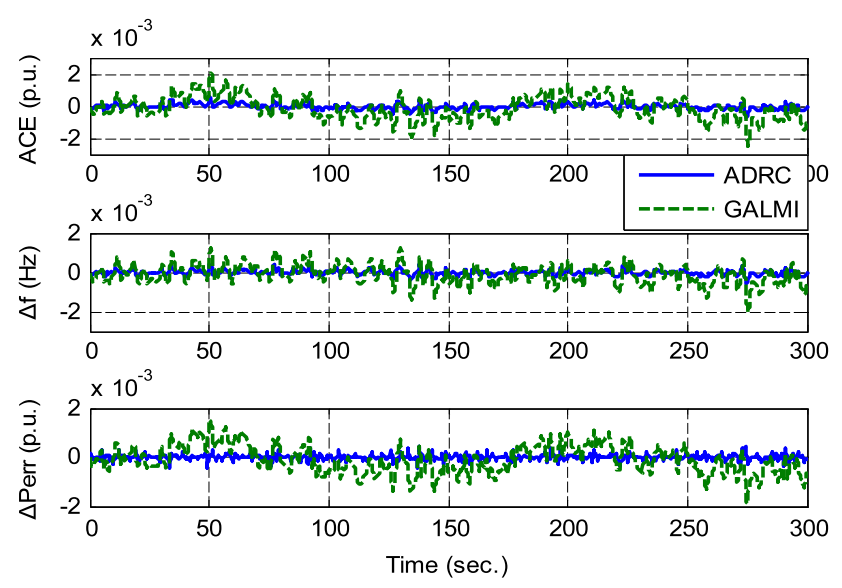

Fig. 13. System responses of area 2 for case 1 .
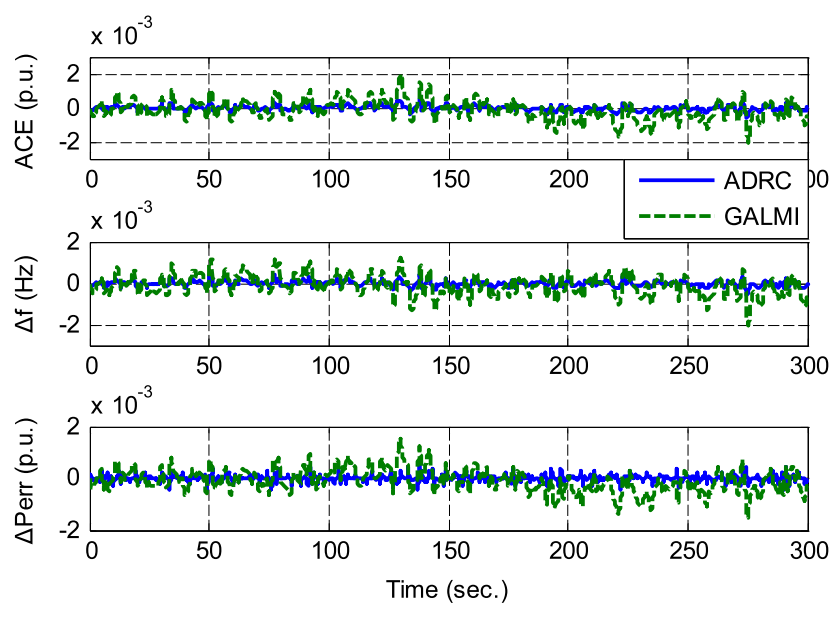

Fig. 14. System responses of area 3 for case 1 .

$\Delta P_{L 2}=80 \mathrm{MW}$ (0.08 p.u.) and $\Delta P_{L 3}=50 \mathrm{MW}(0.05$ p.u. $)$ respectively. The power loads are added to the systems at $t=2 \mathrm{~s}$. The ACE, $\Delta f$ and the control effort for both ADRC and PI controlled systems are shown in Figs. 15-17. ADRC demonstrates smaller oscillations and faster responses in the ACE and $\Delta f$ responses than that of the GALMI tuned PI controller. However, the control effort of ADRC shows an overshoot at the switching edge of the load change. This is due to a slight lag of ESO in response to the external disturbance. But the overshoot magnitude of ADRC is reasonable. So it will not affect the effectiveness of the controller in practice.
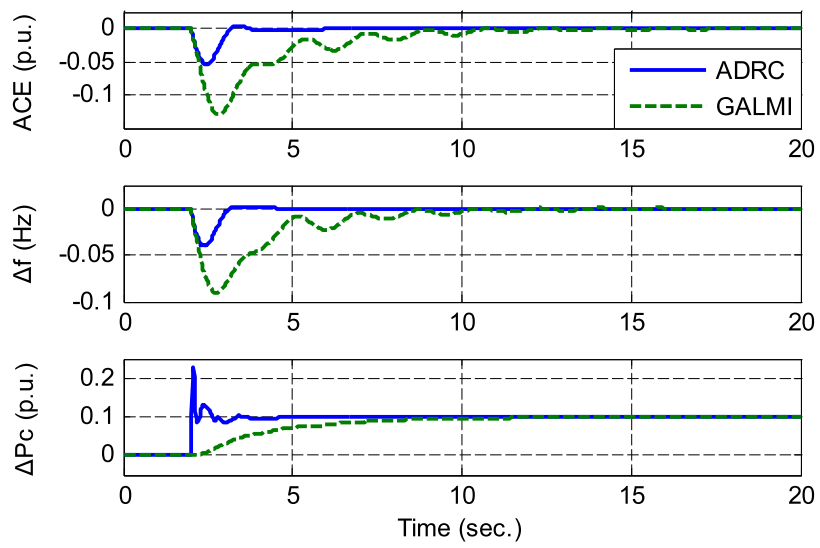

Fig. 15. System responses of area 1 for case 2 .
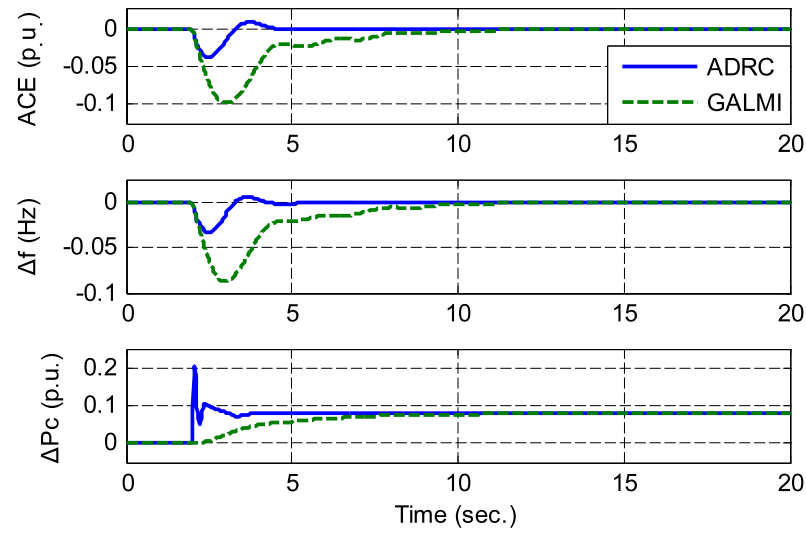

Fig. 16. System responses of area 2 for case 2 .
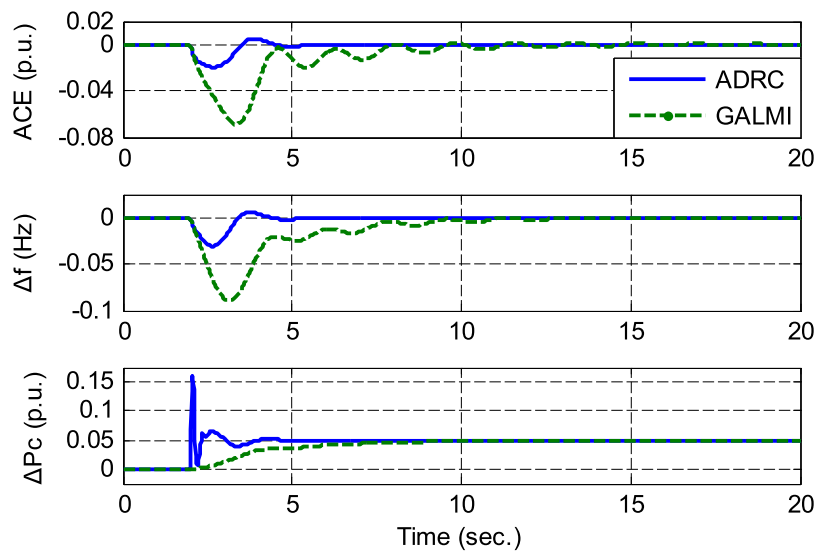

Fig. 17. System responses of area 3 for case 2 .

The purpose of case 3 is to test the stability and effectiveness of ADRC power system under an extreme condition that one generating unit fails to operate. In case 3, Generating company 3 (GenCo3) is cut off at the 20th second while at the 30th second, another $100 \mathrm{MW}$ (0.1 p.u.) step change is loaded on area 1. For case 3 , the same load changes as the ones in case 2 are added to the three areas at $t=2 \mathrm{~s}$. The responses of area 1 are shown in Fig. 18. From the simulation result, we can see that after cutting off the generating company 3 (GenCo3), the GALMI based PI controller drives the ACE to zero with an obvious oscillation since the system model has changed significantly while ADRC is still able to effectively control the system output to track the reference with little overshoot and negligible oscillation. 

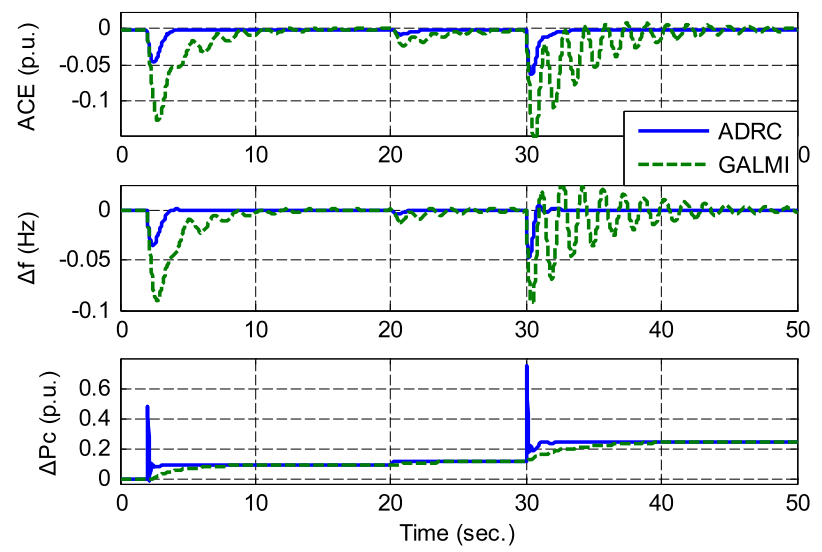

Fig. 18. System responses of area 1 for case 3.

\section{Stability and robustness analyses}

The transfer function representation of ADRC was initially reported in [26], and then applied to MEMS in [23]. In this section, the Laplace transform of the ADRC controlled power system will be developed. Then the frequency-domain analyses will be conducted on the TF representation of the closed-loop system. For the simplicity of description, only Area 1 in Fig. 2 will be used to develop the TF representation. The transfer functions between system inputs $\left(R(s), \Delta P_{L}(s)\right.$ and $\left.\Delta P_{\text {tie }}(s)\right)$ and the ACE output $Y(s)$ for a decentralized non-reheat power generating area (area 1) are given in (7)-(10) in Section 2.

\subsection{Transfer function derivation of closed-loop system}

We start with developing the TF between the reference signal $R(s)$ and the ACE output $Y(s)$ while the other two inputs $\left(\Delta P_{L}(s)\right.$ and $\left.\Delta P_{\text {tie }}(s)\right)$ are assumed to be zeros. Then (6) becomes

$Y(s)=G_{P}(s) U(s)$.

From (10), we can see that area 1 is a third-order system, so we have $n-m=3$. The ESO in (24) can be rewritten as

$s Z(s)=(A-L C) Z(s)+B U(s)+L Y(s)$,

where $Z(s)=\left[z_{1}(s), z_{2}(s), z_{3}(s), z_{4}(s)\right]$. The control law obtained from (27) and (29) can be given by

$U(s)=\left(k_{0} R(s)-K Z(s)\right) / b$,

where $K=\left[k_{0}, k_{1}, k_{2}, 1\right]$. Replacing $U(s)$ in (36) with (37) yields

$Z(s)=[T(s)]^{-1}\left[B k_{0} R(s) / b+L Y(s)\right]$,

where

$T(s)=s I-A+L C+B K / b$.

Replacing $Z(s)$ in (37) with (38) gives

$U(s)=G_{P F}(s) G_{E C}(s) R(s)-G_{E C}(s) Y(s)$,

where $G_{E C}(s)$ is represented by

$G_{E C}(s)=K[T(s)]^{-1} L / b$,

and the pre-filter $G_{P F}(s)$ is represented by

$G_{P F}(s)=\left[k_{0}\left(b-K[T(s)]^{-1} B\right)\right] /\left(b K[T(s)]^{-1} L\right)$.

Replacing the $U(s)$ in (35) with (40), we have

$G_{c l}(s)=\frac{Y(s)}{R(s)}=\frac{G_{P F}(s) G_{E C}(s) G_{P}(s)}{1+G_{E C}(s) G_{P}(s)}$.

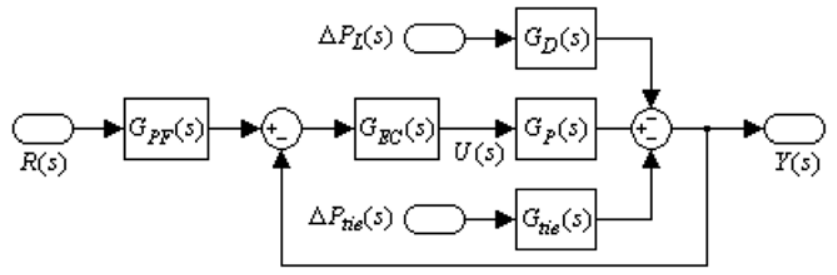

Fig. 19. Block diagram of closed-loop system.

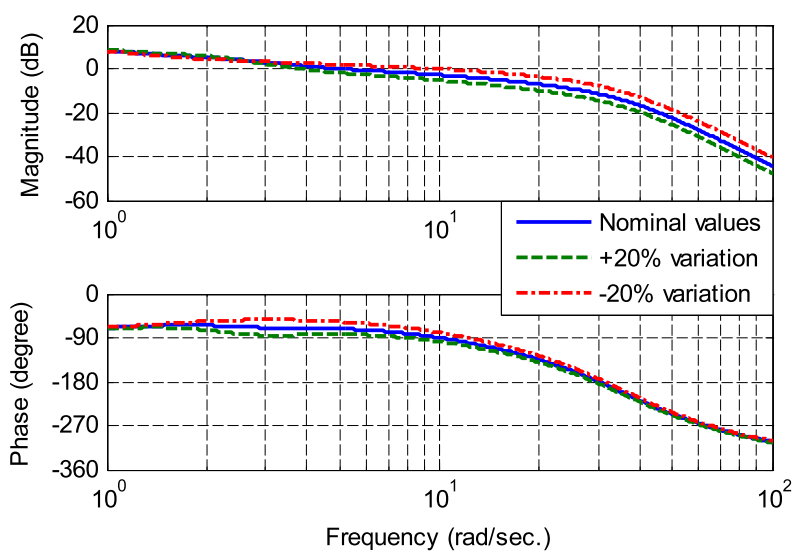

Fig. 20. Frequency responses of $G_{0}(s)$ with different parameters for the non-reheat area.

Table 4

Stability margins for parameter variation test.

\begin{tabular}{llc}
\hline Parameter values & Gain margin $(\mathrm{dB})$ & Phase margin (deg.) \\
\hline Nominal & 11.5 & 108 \\
$+20 \%$ & 14.0 & 96 \\
$-20 \%$ & 8.5 & 103 \\
\hline
\end{tabular}

Table 5

Stability margins for model uncertainty test.

\begin{tabular}{lcl}
\hline GenCos situation & Gain margin $(\mathrm{dB})$ & Phase margin (deg.) \\
\hline Normal & 11.2 & 77 \\
GenCo 3 fails to operate & 9.4 & 74 \\
GenCo 2 \& 3 fail to operate & 10.7 & 51
\end{tabular}

Next, we will develop the TF from the power load $\Delta P_{L}(s)$ to the ACE output $Y(s)$. With $\Delta P_{\text {tie }}(s)=0,(6)$ is changed to

$Y(s)=G_{P}(s) U(s)+G_{D}(s) \Delta P_{L}(s)$.

Since $R(s)=0$, (40) can be rewritten as

$U(s)=-G_{E C}(s) Y(s)$.

Substituting (45) into (44), we obtain the following TF.

$G_{D c l}(s)=\frac{Y(s)}{\Delta P_{L}(s)}=\frac{G_{D}(s)}{1+G_{P}(s) G_{E C}(s)}$.

Similarly, we can get the TF between $\Delta P_{\text {tie }}(s)$ and $Y(s)$ :

$G_{\text {tiecl }}(s)=\frac{Y(s)}{\Delta P_{\text {tie }}(s)}=\frac{G_{\text {tie }}(s)}{1+G_{P}(s) G_{E C}(s)}$.

According to (35)-(47), the closed-loop control system for one area is constructed in Fig. 19. From Fig. 19, the open-loop TF is

$G_{O}(s)=G_{E C}(s) G_{P}(s)$. 
Table 6

Definitions of system parameters.

\begin{tabular}{llll}
\hline$M i^{*}$ & Area Inertia Constant & $D i$ & Area load damping constant \\
$T_{c h} i$ & Turbine time constant & $T_{g} i$ & Governor time constant \\
$R i$ & Speed regulation coefficient & $T i$ & Tie-line synchronizing coefficient between each two areas \\
$F_{h p}$ & High pressure stage rating & $T_{r h}$ & Low pressure reheat time \\
$T_{r}$ & Reset time for hydraulic unit & $R_{t}$ & Temporary droop coefficient \\
$T_{w}$ & Water starting time & $B$ & Area frequency response coefficient \\
\hline
\end{tabular}

Note: The letter $i$ represents the number of an area, and $i=1,2,3$.

Table 7

Parameter values.

\begin{tabular}{|c|c|c|c|c|c|}
\hline \multicolumn{2}{|l|}{ Non-reheat } & \multicolumn{2}{|l|}{ Reheat } & \multicolumn{2}{|l|}{ Hydraulic } \\
\hline M1 (p.u. s.)* & $10 \pm 20 \%$ & M2 (p.u. s.) & 10.0 & M3 (p.u. s.) & 6.0 \\
\hline D1 (p.u./Hz) & $1 \pm 20 \%$ & D2 (p.u./Hz) & 1.0 & D3 (p.u./Hz) & 1.0 \\
\hline Tch 1 (s.) & $0.3 \pm 20 \%$ & Tch2 (s.) & 0.3 & $\operatorname{Tg} 3$ (s.) & 0.2 \\
\hline $\operatorname{Tg} 1$ (s.) & $0.1 \pm 20 \%$ & Fhp & 0.3 & $\operatorname{Tr}$ (s.) & 5.0 \\
\hline$R 1$ (Hz/p.u.) & $0.05 \mp 20 \%$ & $\operatorname{Trh}(\mathrm{s})$. & 7.0 & Rt (Hz/p.u.) & 0.38 \\
\hline \multirow[t]{3}{*}{$T 1$ (p.u./rad.) } & $22.6 \pm 20 \%$ & $\operatorname{Tg} 2$ (s.) & 0.2 & R3 (Hz/p.u.) & 0.05 \\
\hline & & $R 2$ (Hz/p.u.) & 0.05 & $T w(\mathrm{~s})$. & 1.0 \\
\hline & & $T 2$ (p.u./rad.) & 22.6 & T3 (p.u./rad.) & 22.6 \\
\hline
\end{tabular}

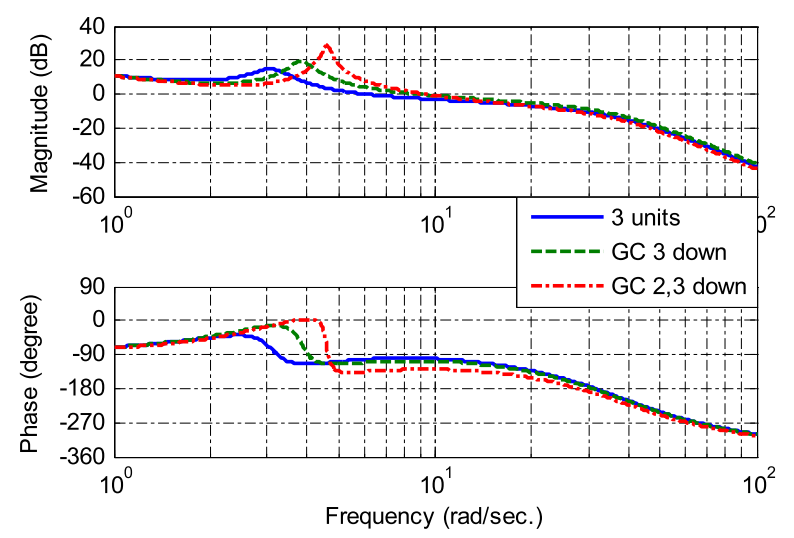

Fig. 21. Bode diagram of the open-loop transfer function $\mathrm{GO}_{\mathrm{O}}(\mathrm{s})$ with model uncertainties.

\subsection{Stability and robustness against parameter variations}

The frequency responses of the open-loop TF represented by (48) are shown in Fig. 20, in which the system parameters of area 1 $\left(M_{1}, D_{1}, T_{c h 1}, T_{g 1}, R_{1}\right.$, and $\left.T_{1}\right)$ in Fig. 2 are varying from $-20 \%$ to $20 \%$ of their nominal values. The stability margins of the system with system uncertainties are listed in Table 4. The Bode Diagram and stability margins demonstrate the stability of the ADRC controlled power system in the presences of $\pm 20 \%$ parameter variations in the selected area.

\subsection{Stability ad robustness against model uncertainties}

In this part, we will utilize the second test power system to test the stability and robustness of ADRC system. The block diagram of this power system is shown in Fig. 10. For contingency test, we suppose two extreme situations. In this first situation, the power generating company GenCo2 fails to operate. In the second extreme situation, both the power generating companies GenCo2 and GenCo3 fail to operate. In both situations, the controller parameters of ADRC remain unchanged. Then the Bode diagram of the open-loop transfer function (48) with the unchanged ADRC is shown in Fig. 21. The stability margins are listed in Table 5. From the Bode diagram and the stability margins, we can see that ADRC is quite stable and reliable under the extreme situations.

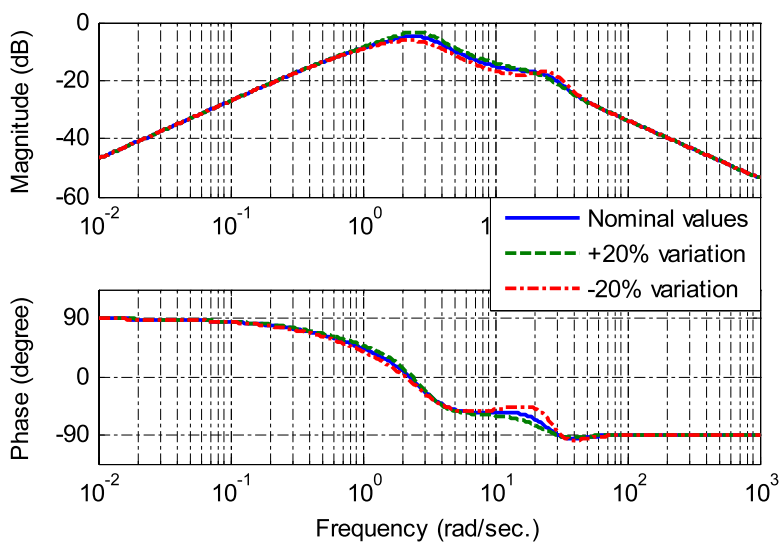

Fig. 22. Frequency responses of $G_{D c l}(s)$ with variant parameters for the non-reheat area.

\subsection{External disturbance rejection}

Eq. (46) gives the transfer function between ACE output and active power load input $\left(\Delta P_{L}(s)\right)$. For the selected area 1 , the Bode diagram of this transfer function (46) is shown in Fig. 22, where the system parameters $\left(M_{1}, D_{1}, T_{c h 1}, T_{g 1}, R_{1}\right.$, and $\left.T_{1}\right)$ are varying from $-20 \%$ to $20 \%$ of their nominal values.

Fig. 22 successfully proves the disturbance rejection ability of the desired LFC controller (ADRC) since the magnitude responses are under $0 \mathrm{~dB}$ at any input frequency. In addition, the frequency responses are almost unchanged with the changes of system parameters. This also verified the robustness of the control system against internal uncertainties.

\section{Concluding remarks}

As an increasingly popular practical control method [23-27], ADRC has the advantage of requiring little information from the plant model. Specifically the controller mainly needs the relative order $(n-m)$, output data and controller gain $(b)$ from the power plant. This advantage makes the controller very robust against system uncertainties. In addition, compared to the PID controller with three tuning parameters [8-12], ADRC only has two $\left(\omega_{c}\right.$ and $b)$. The controller bandwidth $\omega_{c}$ can be selected based on the performance requirement such as the settling time constraint. The parameter $b$ is a plant parameter either known to the designer or can be determined from open loop response. The two-tuningparameter feature enables simple implementation of the ADRC in the real world.

An ADRC-based decentralized LFC for interconnected threearea power systems is presented in this paper to regulate ACE in the presences of load changes and system uncertainties. The ADRC is designed for the power system containing both thermal and hydraulic turbines. The frequency-domain analyses demonstrated the effectiveness of the controller. The simulation results verified the stability and robustness of the ADRC. The comparison study in Section 4 also proved the superiority of the ADRC to the GALMI tuned PI Controller that is a dominant controller in power industry. 
For future research, we will study singularities of speed governor such as rate limits on valve position and generation rate constraints and will use ADRC to compensate for such singularities. We are also going to simulate the ADRC controlled power system in Simplorer, a powerful CAD tool in modeling real power systems. We will use this CAD tool to test the controller and to ensure its applicability in power industries

\section{Appendix}

\section{See Tables 6 and 7.}

\section{References}

[1] Kundur P. Power System Stability and Control. McGraw-Hill; 1994.

[2] Jaleeli N, Vanslyck LS, Ewart DN, Fink LH, Hoffmann AG. Understanding automatic generation control. IEEE Transactions on Power Systems 1992;7(3): $1106-22$.

[3] Ibraheem PK, Kothari DP. Recent philosophies of automatic generation control strategies in power systems. IEEE Transactions on Power Systems 2005;20(1): 346-57.

[4] Tomsovic K, Bakken DE, Venkatasubramanian V, Bose A. Designing the next generation of real-time control, communication, and computations for large power systems. Proceedings of the IEEE 2005;93(5):965-79.

[5] Kothari M, Sinha N, Rafi M. Automatic generation control of an interconnected power system under deregulated environment. Power Quality 1998;18: 95-102.

[6] Donde V, Pai MA, Hiskens IA. Simulation and optimization in an AGC system after deregulation. IEEE Transactions on Power Systems 2001;16:481-9.

[7] Okada K, Yokoyama R, Shirai G, Sasaki H. Decentralized load frequency control with load demand prediction in multi-area power systems. Proceedings of International Conference on Control 1988;13(15):649-54

[8] Aldeen M, Sharma R. Robust detection of faults in frequency control loops. IEEE Transactions on Power Systems 2007;22(1):413-22.

[9] Bevrani H, Hiyama T. Robust decentralized PI based LFC design for time delay power systems. Energy Conversion and Management 2008;49(2):193-204.

[10] Moon Y, Ryu H, Lee J, Kim S. Power system load frequency control using noise-tolerable PID feedback. IEEE International Symposium on Industrial Electronics 2001;3:1714-8.

[11] RerkPreedapong D, Hasanovic A, Feliachi A. Robust load frequency control using genetic algorithms and linear matrix inequalities. IEEE Transactions on Power Systems 2003;18(2):855-61.

[12] Yu X, Tomsovic K. Application of linear matrix inequalities for load frequency control with communication delays. IEEE Transactions on Power Systems 2004;19(3):1508-15.

[13] Tan W. Unified tuning of PID load frequency controller for power systems via IMC. IEEE Transactions on Power Systems 2010;25(1):341-50.
[14] Panda G, Panda S, Ardil C. Automatic generation control of interconnected power system with generarion rate constraints by hybrid neuro fuzzy approach. International Journal of Electrical Power and Energy Systems Engineering 2009;2(1):13-8.

[15] Ohba S, Ohnishi H, Iwamoto S. An advanced LFC design considering parameter uncertainties in power systems. IEEE Transactions on Power System 2007; 7(3):630-5.

[16] Bensenouci A, Ghany A. Mixed $\mathrm{H}_{\infty} / \mathrm{H}_{2}$ with pole-placement design of robust LMI-based output feedback controllers for multi-area load frequency control. In: Proceedings of the International Conference on Computer as a Tool. Warsaw, Poland; Sep. 2007. p. 1561-1566.

[17] Rerkpreedapong D, Feliachi A. Decentralized $\mathrm{H}_{\infty}$ load frequency control using LMI control toolbox. In: The 2003 International Symposium on Circuits and Systems. vol. 3, no. 25-28; May 2003. p. 411-4.

[18] Kong L, Xiao L. A new model predictive control scheme-based load-frequency control. In: Proceedings of IEEE International Conference on Control and Automation. Guangzhou, China; Jun. 2007. p. 2514-8.

[19] Rubaai A, Udo V. Self-tunning load frequency control: multilevel adaptive approach. In: IEEE Proceedings of Generation. Transmission and Distribution. vol.7, no. 3; Jul. 1994. p. 285-90.

[20] Bevrani H, Mitani Y, Tsuji K. Robust load frequency regulation in a new distributed generation environment. In: Proceedings of Power Engineering Society General Meeting. vol. 2; Jul. 2003. p. 548-53.

[21] Hiyama T, Koga S, Yoshimuta Y. Fuzzy logic based multi-functional load frequency control. In: Proceedings of IEEE Power Engineering Society 2000 Winter Meeting. vol. 2; Jan. 2000. p. 921-6.

[22] Yukita K, Goto Y, Mizuno K, Miyafuji T, Ichiyanagi K, Mizutani Y. Study of load frequency control using fuzzy theory by combined cycle power plant. In: IEEE Power Engineering Society 2000 Winter Meeting. vol. 1; Jan. 2000. p. 422-7.

[23] Dong L, Avanesian D. Drive-mode control for vibrational MEMS gyroscopes. IEEE Transactions on Industrial Electronics 2009;56(4):956-63.

[24] Sun B, Gao Z. A DSP-based active disturbance rejection control design for a 1-kW H-bridge DC-DC power converter. IEEE Transactions on Industrial Electronics 2005;52(5):1271-7.

[25] Gao Z. Active disturbance rejection control: a paradigm shift in feedback control system design. In: Proceedings of American Control Conference. Minneapolis, MN; Jun. 2006. p. 2399-405.

[26] Tian G, Gao Z. Frequency response analysis of active disturbance rejection based control system. In: Proceedings of IEEE International Conference on Control Applications. Singapore; Oct. 2007. p. 1595-9.

[27] Zhou W, Gao Z. An active disturbance rejection approach to tension and velocity regulations in web processing lines. In: IEEE International Conference on Control Applications. Singapore; Oct. 2007. p. 842-8.

[28] Gao Z Scaling and bandwidth-parameterization based controller tuning In: Proc. of American Control Conference. Denver, CO; June 2003. vol. 6. p. 4989-96.

[29] Zhang Y, Dong L, Gao Z. Load frequency control for multi-area power system. In: Proceedings of American Control Conference. St. Louis, MI; Jun. 2009. p. 2773-8. 